\title{
Optimasi Konsentrasi Amylum Sagu (Metroxylon rumphii) sebagai Co-Processed pada Pembuatan Tablet Teofilin
}

\section{Optimization of Sago Amylum Concentration (Metroxylon rumphii) as Co-Processed in Theophylline Tablets}

\author{
Nor Laili, Annisa' Meyndra Komala, Hidayaturrizqika Maulida, Suprapto* \\ Fakultas Farmasi, University of Muhammadiyah Surakarta \\ *email: suprapto@ums.ac.id
}

\begin{abstract}
ABSTRAK
Sediaan tablet banyak digunakan masyarakat untuk pengobatan, sehingga tingkat produksi sediaan tablet cukup besar dan selalu mengalami perkembangan dalam formulasinya. Eksipien yang umumnya digunakan berupa $95 \%$ bahan impor yang relatif mahal sehingga biaya produksi akan berpengaruh pada harga sediaan tablet yang akan lebih mahal. Berdasarkan pertimbangan tersebut, penelitian ini menggunakan eksipien bahan alam Indonesia dengan biaya relatif rendah berupa amylum sagu. Penelitian ini mengkombinasikan amylum sagu dan Avicel pH 101 dengan 5 variasi konsentrasi, yaitu 90\%:10\% (formula 1), 80\%:20\% (formula 2), 70\%:30\% (formula 3), 60\%:40\% (formula 4), dan 50\%:50\% (formula 5) yang menghasilkan suatu co-processed eksipien. Co-processed ini diaplikasikan dalam pembuatan tablet Teofilin sebagai bahan pengisi, pengikat dan penghancur dengan metode cetak langsung dan diuji berdasarkan parameter pada Farmakope Indonesia Edisi V. Analisis data menggunakan software Design Expert ${ }^{\circledR}$ versi 11 untuk mendapatkan formula optimum. Karakterisasi co-processed yang dihasilkan memiliki sifat alir optimum yaitu $11,11 \mathrm{~g} / \mathrm{dtk}$, kompresibilitas $=3,0 \%$, dan sudut diam $=32,0^{\circ}$ serta evaluasi terhadap mutu tablet keseragaman bobot $\mathrm{CV}=10,3$, kekerasan $\bar{x}=6,2 \mathrm{~kg}$, kerapuhan $=1,8 \%$, dan waktu hancur 46,2 detik, Berdasarkan analisis dengan metode Simplex Lattice Design membuktikan bahwa semakin banyak konsentrasi amylum sagu meningkatkan kerapuhan dan menurunkan kekerasan, Sedangkan semakin banyak Avicel pH 101 menurunkan kerapuhan dan meningkatkan kekerasan. Kesimpulan dengan analisis software Design Expert didapatkan formula optimum co-processed berupa kombinasi 50\% pasta amylum; 18,18\% amylum sagu; dan 31,82\% avicel PH 101.
\end{abstract}

Kata kunci: Amylum-Sagu, Avicel PH 101, Co-processed, Tablet, Teofilin.

\begin{abstract}
Tablet preparations are widely used many people for treatment, so the level of production of tablet preparations is quite large and always develops in its formulation. Excipients are generally used in the form of $95 \%$ imported materials which are relatively expensive so that production costs will affect the price of tablet preparations which will be more expensive. Based on these considerations, this study uses Indonesian natural excipient with a relatively low cost in the form of sago amylum. This study combines sago amylum and Avicel pH 101 with 5 concentration variations, 90\%: 10\% (formula 1), 80\%: 20\% (formula 2), 70\%: 30\% (formula 3), 60\%: 40\% (formula 4), and 50\%: 50\% (formula 5) which produces a co-processed excipient. This co-processed was applied in the manufacture of the Theophylline tablet as a filler, binder and shredder with the direct compression method and tested based on parameters in the Indonesian Pharmacopoeia V. Data analysis using Design Expert@ version 11 software to obtain the optimum formula. The co-processed characterization produced has optimum flow properties which are $11.11 \mathrm{~g} / \mathrm{sec}$, compressibility $=3.0 \%$, and the stationary angle $=32.0^{\circ}$ and evaluation of tablet quality uniformity $C V=$ 10.3, hardness $\bar{x}=6,2 \mathrm{~kg}$, fragility $=1.8 \%$, and 46.2 seconds destroyed time. Based on the analysis by Simplex Lattice Design method, it is proved that the more amylum sago concentration increases friability and decreases hardness, while more of Avicel pH 101 decreases friability and increases hardness. It is concluded with the Design Expert software analysis, the optimum co-processed formula was obtained in the form of a combination of 50\% sago amylum; 18,18\% pasta amylum sago and 31.82\% Avicel pH 101.
\end{abstract}

Keywords: Amylum-Sago , Avicel PH 101, Co-processed, Tablet, Theophylline 


\section{PENDAHULUAN}

Sediaan tablet mengandung komponen eksipien atau bahan tambahan yang mempunyai fungsi tertentu. Eksipien dapat berupa bahan pengisi, bahan pengikat, bahan penghancur, bahan pelicin, serta jika perlu bahan pewarna, bahan perasa, dan bahan penyalut (Tomar M et al, 2017). Eksipien yang umumnya digunakan bahan impor dimana harga produksi akan berpengaruh pada harga sediaan dipasaran yang relatif mahal. Berdasarkan pertimbangan fungsional dan harga maka dimanfaatkan bahan alam Indonesia berupa amylum sagu sebagai eksipien dalam formulasi tablet. Kombinasi eksipien adalah kombinasi zat dengan fungsi yang berbeda,hal itu menghasilkan zat multifungsi, yang secara nyata mempersingkat proses produksi tablet dan berpengaruh dengan harga (Muzikova $\mathrm{J}$ et al, 2016)

Proporsi setiap eksipien berpengaruh pada sifat fisik tablet, misalkan kurang optimumnya penggunaan satu macam eksipien maka dikembangkan co-processed excipient yang mengombinasikan dua atau lebih bahan pengisi, dirancang secara fisik dengan memodifikasi sifat dari setiap eksipien dengan metode optimasi tertentu (Lachman, 2014 ).

Tujuan dari penelitian ini adalah untuk mendapatkan perbandingan konsentrasi amylum sagu-avicel $\mathrm{pH} 101$ dalam formula optimum tablet teofilin, mengetahui pengaruh konsentrasi amylum sagu-avicel pH 101 terhadap sifat fisik tablet teofilin. Penggunaan Avicel pH 101 pada tablet baik sebagai pengisi maupun penghancur memberikan waktu hancur dan pelepasan obat dalam waktu yang singkat serta memiliki kompresibilitas yang baik sehingga cocok untuk dijadikan bahan co-processed (Kuentz M et al, 2016).

Keuntungan menggunakan bahan Coprocessed dapat mengurangi jumlah bahan tambahan yang digunakan dan waktu proses yang diperlukan dalam formulasi. Salah satu contoh bahan co-processed adalah campuran dari MMC dan koloidal silika dioksid, yang memiliki keuntungan dapat meningkatkan kekerasan tablet, meningkatkan retensi kompresibilitas setelah proses granulasi, serta mempunyai sifat alir yang lebih baik dibandingkan dengan menggunakan MMC atau koloidal silika dioksid secara tunggal (Hadisoewigno, L.,dkk., 2013).

Untuk melihat formula optimum kombinasi amylum sagu dan avicel PH 10 sebagai bahan pengisi, bahan pengikat sekaligus bahan penghancur maka akan dilakukan sebuah optimasi formula menggunakan metode factorial design. Penelitian mengenai amylum sagu dan avicel ini diharapkan dapat menjadi pilihan varian baru dan bermanfaat sebagai bahan dalam formula co processed excipient serta meningkatkan penggunaan bahan alam sebagai salah satu komponen dalam formulasi tersebut.

\section{METODE PENELITIAN Waktu dan Tempat}

Penelitian ini dilakukan selama bulan Mei sampai Juni 2018. Pengujian terhadap mutu fisik tablet dilakukan di Laboratorium Formulasi dan Teknologi Sediaan Fakultas Farmasi UMS sedangkan uji SEM dilakukan di Laboratorium UGM.

\section{Alat dan Bahan}

Alat utama dalam penelitian ini adalah alat uji sifat alir, alat pencetak tablet (Hidroulic Press), alat uji kekerasan tablet (Vanguard Pharmaceutical Machinery), alat uji kerapuhan (Vanguard Pharmaceutical Machiner), alat uji waktu hancur (Vanguard Pharmaceutical Machiner) dan Spektrofotometer Genesys 10 (Shizimadzu), Oven (G-Binder), Hotplate (Thermo Scientific), Timbangan analytic (Ohaus).

Bahan yang digunakan dalam penelitian ini adalah teofilin (PT.Bratachem), amylum sagu (PT.Pondasi Inti Sejahtera), Avicel PH 101 (PT.Bratachem), Croscarmellose Sodium (PT Signa Husada.) dan Magnesium stearat (PT. Bratachem).

Desain Formula 
Penelitian ini menggunakan optimasi formula dari Simplex Lattice Design dibuat dengan perbedaan konsentrasi amylum sagu dan Avicel pH 101 dapat dilihat pada Tabel 1. Pembuatan Co-Processed dilakukan dengan pengulangan 3 kali. (Hauschild dan Picker, 2004).

Uji Co-Processed AS-A Sebagai Bahan Pengisi Tablet

Uji Keseragaman Bobot Tablet: Ambil

Tabel 1. Formula Co-Processed Amylum Sagu dan Avicel PH 101

\begin{tabular}{lccccc}
\hline \multirow{2}{*}{ Bahan } & \multicolumn{5}{c}{ Komposisi (\%) } \\
\cline { 2 - 6 } & CP1 & CP2 & CP3 & CP4 & CP5 \\
\hline Avicel pH 101 & 10 & 20 & 30 & 40 & 50 \\
Amylum Sagu & 40 & 30 & 20 & 10 & 0 \\
Pasta Amylum Sagu & 50 & 50 & 50 & 50 & 50 \\
Jumlah Bahan (\%) & 100 & 100 & 100 & 100 & 100 \\
\hline
\end{tabular}

Tabel 2. Formula Tablet Teofilin

\begin{tabular}{lccccc}
\hline Bahan & \multicolumn{5}{c}{ Berat (mg) } \\
\cline { 2 - 6 } & F1 & F2 & F3 & F4 & F5 \\
\hline Teofilin (bahan aktif) & 150 & 150 & 150 & 150 & 150 \\
Co-processed AS-A & 300 & 300 & 300 & 300 & 300 \\
Crosscarmellose Sodium (bahan penghancur) & 3 & 3 & 3 & 3 & 3 \\
Magnesium stearate 2\% (bahan pelicin) & 7 & 7 & 7 & 7 & 7 \\
Berat Tablet & 100 & 100 & 100 & 100 & 100 \\
\hline
\end{tabular}

Amylum sagu dan Avicel pH 101 dengan perbandingan tertentu (Tabel I) dihomogenkan di dalam mortir. Digranulasi dengan pasta amylum sagu dan diayak dengan pengayak No. 12. Co-Processed yang terbentuk dikeringkan dengan lemari oven selama 3 jam bersuhu $60 \mathrm{C}$. Co-Processed kering diayak dengan pengayak No.14.

\section{Pembuatan Tablet}

Pembuatan tablet menggunakan metode cetak langsung. Granul Co-Processed yang telah dihaluskan, dicampur dengan Teofilin, Crosscarmellose Sodium, dan Magnesium Stearat dengan formula dapat dilihat di Tabel 2.

\section{Karakterisasi Sediaan Eksipien}

Organoleptis: pengamatan meliputi warna, bentuk, dan ukuran mikronya.

Berat Jenis: Granul dimasukkan dalam gelas ukur $100 \mathrm{~mL}$, kemudian dilakukan pengetapan hingga volume konstan nya tercapai.

Kecepatan Alir dan Sudut Diam: Kecepatan alir dan sudut diam co-process AS-A diuji dengan metode corong. Sampel co-process AS-A yang digunakan setiap pengujian adalah 100 gram. Pengujian
30 tablet masing-masing formula, ditimbang bobot rata-rata dan diperiksa penyimpangan bobot tablet.

Uji Kekerasan Tablet: Menggunakan alat hardness tester dengan 5 tablet yang diuji.

Kerapuhan: Tablet yang diuji sebanyak 20 tablet, terlebih dahulu dibersihkan dari debunya dan ditimbang seksama. Tablet dimasukkan ke dalam Friabilator dan diputar sebanyak 100 putaran selama 4 menit. Setelah selesai, keluarkan tablet dari alat dan dibersihkan dari debu. Dihitung persentase kehilangan bobot.

Uji Waktu Hancur: Dimasukkan 6 tablet pada masing-masing lubang di tabung, gunakan aquadest bersuhu $37 \mathrm{C}$. Amati kesesuaian waktu hancur dengan monografi tablet tidak bersalut (kurang dari 15 menit) .

Uji Disolusi: Uji disolusi dilakukan dengan kecepatan dayung 50 rpm dengan media disolusi aquadest $900 \mathrm{~mL}$. Pada masing-masing tabung diletakkan 1 tablet Teofilin. Penetapan jumlah kadar yang terlarut menggunakan spektrofotometer UV di menit ke-5,10,15,30, dan 45 .

\section{Analisis Data}

Analisis statistik terhadap data formula optimum dari formulasi sediaan eksipien 
Tabel 3. Sifat granul co-processed

\begin{tabular}{cccc}
\hline Co-Processed & $\begin{array}{c}\text { Sudut Diam } \\
\left(\Theta^{\circ}\right)\end{array}$ & $\begin{array}{c}\text { Sifat Alir } \\
(\text { gr/detik) }\end{array}$ & \% Kompresibilitas \\
\hline F1 & 30,40 & 10,28 & 6 \\
F2 & 33,04 & 6,00 & 4 \\
F3 & 30,77 & 10,87 & 3 \\
F4 & 32,28 & 8,90 & 3 \\
F5 & 33,17 & 9,54 & 3 \\
\hline
\end{tabular}

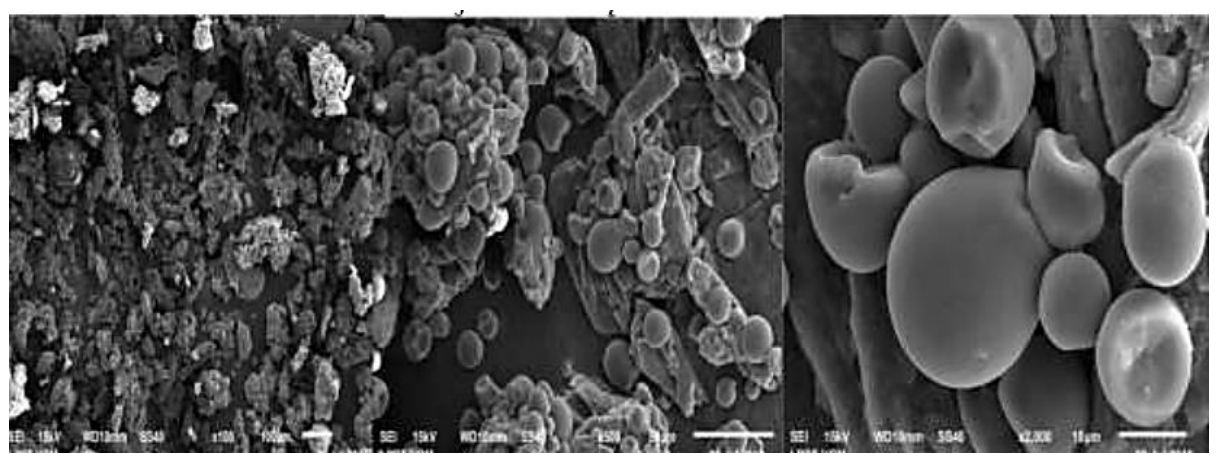

Gambar 1. Hasil Uji SEM co-processed AS-A

kombinasi amylum sagu dan Avicel PH 101 dilakukan menggunakan software Design Expert.

\section{HASIL DAN PEMBAHASAN}

Pencampuran amylum sagu dengan avicel PH 101 sampai homogen kemudian di granulasi dengan pasta amylum sampai terbentuk massa yang baik lalu diayak dengan ayakan no. 12 dan diikeringkan pada suhu $60^{\circ}$ $\mathrm{C}$ selama 3 jam. Pengayakan bertujuan agar granul yang terbentuk memiliki ukuran yang seragam sehingga kompresibilitas dari granul optimum. Kompresibilitas yang baik bertujuan agar tablet yang terbentuk mempunyai kekuatan yang baik sehingga tidak rentan rapuh dalam perjalanan. Setelah dilakukan pengeringan granul kembali diayak dengan ayakan no. 14. Kemudian dilakukan pengujian terhadap granul yang telah dibuat. Pengujian yang dilakukan terhadap granul yaitu sifat alir, sudat diam, kompresibilitas, dan organoleptik meliputi warna dan bentuk dari granul yang dibuat. Organoleptik dari granul yang dibuat berwarna putih dengan bentuk granul membulat.

Dilakukan pengamatan pengujian uji sem (Gambar 1), berdasarkan hasil uji SEM dapat melihat morfologi co-processed AS-A yakni terbentuknya ikatan sehingga granul menjadi lebih besar. Terdapat berbagai bentuk komponen yaitu bentuk amylum sagu yang berbentuk bulat dan sebagian lagi mengalami perubahan bentuk karena dilakukan pemanasan pada suhu $60^{\circ} \mathrm{C}$ sedangkan avicel PH 101 berbentuk lebih panjang seperti batang. Granul yang besar bertujuan meningkatkan sifat alir sehingga kepadatan dan kekerasan tablet meningkat dan menurunkan kerapuhan tablet.

Sifat fisik dari granul co-processed Amylum sagu dan Avicel ditampilkan pada tabel 3 yaitu sudut diam, sifat alir dan berat jenis. Menurut Hadisoewignyo, L., dan Fudholi, A., 2013 sifat alir yang baik apabila 100 gram granul dapat mengalir dalam waktu kurang dari 10 detik artinya dalam waktu satu detik terdapat lebih dari 10 gram granul yang mengalir. Misalnya formula ke- 3 sifat alir lebih dari 10 gram yaitu 10,87 gr/dt. Sifat alir merupakan hal yang kritis dalam produksi obat sediaan padat. Sifat alir granul memegang peranan penting dalam pembuatan tablet, sehingga menyebabkan keseragaman bobot sediaan padat lebih baik. Terdapat beberapa faktor yang mempengaruhi sifat alir 
serbuk atau tablet, yaitu kerapatan, porositas, ukuran dan bentuk partikel, kondisi percobaan, dan kandungan lembab. pencetakan tablet hal ini untuk menjaga konsistensi dari massa tablet yang akan dibuat. Pengujian selanjutnya yaitu uji

Tabel 4. Sifat Tablet Teofilin

\begin{tabular}{lccccc}
\hline \multicolumn{1}{c}{ Uji } & F1 & F2 & F3 & F4 & F5 \\
\hline Keseragaman Bobot (CV) & 11,305 & 14,582 & 9,58 & 9,195 & 10,060 \\
Kekerasan (kg) & 3,12 & 5,398 & 8,425 & 5,76 & 7,68 \\
Kerapuhan (\%) & 1,939 & 2,4 & 1,7 & 1,568 & 1,406 \\
Waktu Hancur (Detik) & 43 & 45 & 47 & 45 & 46 \\
\hline
\end{tabular}

Waktu alir adalah waktu yang diperlukan untuk mengalir dari sejumlah granul melalui lubang corong dalam waktu tertentu. Dengan mengukur waktu alirnya, dapat diketahui kecepatan alir dari suatu granul. Uji sifat alir dapat dilakukan dengan metode langsung dan metode tidak langsung, namun pada percobaan ini menggunakan metode tidak langsung. Metode tidak langsung yaitu pengamatan sudut diam dengan corong dan metode pengetapan. Sudut diam merupakan sudut evaluasi permukaan bebas setumpuk partikel terhadap bidang datar. Pengamatan dilakukan dengan mengukur tinggi kerucut serbuk yang terbentuk pada bidang horizontal, dengan diameter tertentu. Pada saat mengalirkan serbuk, diusahakan tidak ada getaran agar terbentuk kerucut sempurna.

Kemudian menurut Ahmad Fudholi, 2013 sudut diam sangat baik jika masuk ke dalam rentang $25-30 \Theta^{\circ}$ dan dikatakan baik jika masuk rentang $30-35 \Theta^{\circ}$. Berdasarkan penelitian yang kami lakukan maka formula 1 $(30,40)$ dan $3(30,70)$ memiliki sudut diam yang sangat baik. Pada pengamatan sudut diam, secara teoritis menyatakan bahwa ukuran partikel berbanding terbalik dengan sudut diam. Semakin kecil kecil sudut diam, sifat alir semakin baik. Hasil praktikum yang diperoleh menunjukkan semakin kecil ukuran partikel, sudut diam yang diperoleh semakin kecil, namun padapercobaan terjadi peningkatan sudut diam pada ukuran granul 16/20 mesh. Berdasarkan nilai hasil diam yang diperoleh, sifat alir yang diperoleh baik. Sifat alir sangat penting dalam pengetapan, dimana merupakan uji yang didasarkan pada penataan susunan partikel penyusun dalam suatu wadah sebelum dan sesudah diberikan perlakuan getaran mekanik dengan alat volumenometer hingga terbentuk volume yang konstan. Semakin besar harga $\mathrm{T}(\%)$, sifat alir makin buruk. Serbuk dikatakan memiliki sifat alir yang baik jika indeks pemampatannya kurang dari $20 \%$ yang berarti semua formula sesuai dengan spesifikasi granul yang baik. Hasil percobaan menunjukkan bahwa serbuk memiliki sifat alir baik, yang ditandai dengan nilai T\% yang kurang dari $20 \%$. Berdasarkan percobaan pengetapan, diperoleh juga nilai indeks Carr's atau persen kompresibilitas. Hasil perhitungan yang diperoleh, nilai indeks Carr's percobaan berada pada rentang 3-6\%, perhitungan indeks Carr's ini menunjukkan bahwa serbuk memiliki sifat alir yang sangat baik. Kompresibilitas berperan dalam menentukan kekerasan dan kekompakkan suatu sediaan tablet, semakin kecil nilai kompresibilitas maka nilai kekerasan tablet akan meningkat. Tablet harus memiliki kekerasan yang optimum, nilai kekerasan tablet tidak boleh terlalu kecil karena tablet akan mudah rapuh dan hancur dalam proses distribusi obat dari industri ke konsumen.

Sedangkan jika nilai kekerasan tablet terlalu tinggi, tablet akan sulit hancur dalam saluran cerna sehingga waktu yang diperlukan untuk absobsi obat lebih lama.

Dilakukan beberapa pengujian sifat tablet (Tabel 4), diawali dengan uji keseragaman bobot yang bertujuan untuk memngetahui tablet yang dibuat memiliki 
bobot yang seragam/tidak antara tablet satu dengan lainnya. Hal ini juga untuk memastikan bahwa dosis tiap tablet adalah sama, agar dapat memberikan efek terapi yang sama.

Uji yang kedua adalah Uji kekerasan tablet digunakan untuk menggambarkan ketahanan tablet dalam melawan tekanan mekanik seperti goncangan, kikisan dan terjadi keretakan tablet selama proses pengemasan, distribusi ataupun saat penyimpanan. Alat yang digunakan untuk menguji kekerasan tablet adalah tablet Hardness Tester. Beberapa faktor yang mempengaruhi kekerasan tablet seperti tekanan kompresi dan sifat bahan yang dikempa. Kekerasan ini dipakai sebagai ukuran dari tekanan pengempaan. Semakin besar tekanan yang diberikan saat penabletan akan meningkatkan kekerasan tablet. Pada umumnya tablet yang keras memiliki waktu hancur yang lama (lebih susah hancur) dan disolusi yang rendah (tidak mutlak).

Uji kerapuhan menggunakan friabilator, yang merupakan parameter untuk mengukur ketahanan permukaan tablet terhadap gesekan yang dialaminya sewaktu pengemasan dan pengiriman. Prinsipnya adalah menetapkan bobot yang hilang dari sejumlah tablet selama diputar dalam friabilator selama waktu tertentu. Uji kerapuhan berhubungan dengan kehilangan bobot akibat abrasi yang terjadi pada permukaan tablet. Semakin besar harga persentase kerapuhan, maka semakin besar massa tablet yang hilang. Kerapuhan yang tinggi akan mempengaruhi konsentrasi/kadar zat aktif yang masih terdapat pada tablet.

Uji waktu hancur menggunakan disintegrator tester memberikan gambaran tentang waktu yang dibutuhkan sejumlah tablet hancur menjadi granul atau partikel penyusunnya ketika kontak dengan cairan. Kecepatan waktu hancur suatu obat berpengaruh terhadap kecepatan efek farmakologinya, semakin cepat waktu hancur maka obat akan cepat diabsorpsi dan kemungkinan akan semakin cepat pula menimbulkan efek farmakologis. Persyaratan waktu hancur untuk tablet tidak bersalut adalah kurang dari 15 menit.

Untuk beberapa parameter pengujian dimana disebutkan bahwa persyaratan untuk tablet oral tidak bersalut yaitu $\mathrm{CV}$ keseragaman bobot kurang dari 15\%, kekerasan 4-10 kg (Achmad Fudholi 2013), kerapuhan $0,5 \%$ - $1 \%$ (Lachman), dan waktu hancur kurang dari 15 menit (Farmakope Indonesia Edisi V). Berdasarkan beberapa parameter tersebut sifat masing-masing tablet yang terdapat pada tabel 4 dapat disimpulkan bahwa keseragaman bobot, kekerasan, dan waktu hancur sudah memenuhi persyaratan tablet tetapi untuk kerapuhan masih melebihi 1\%. Uji kerapuhan berhubungan dengan kehilangan bobot akibat abrasi yang terjadi pada permukaan tablet.

Hasil uji disolusi dihitung menggunakan persamaan $\mathrm{y}=0,3945 \mathrm{x}+0,08$ (Tabel 5). Menurut Farmakope Indonesia Edisi V yang baik untuk teofilin adalah lebih dari $70 \%$. Pada formula yang diuji dalam waktu 45 menit \% terdisolusi pada formula $18,42 \%$; formula $217,58 \%$; formula 36,24 ; formula 4 $22,01 \%$; dan formula $58,94 \%$. Nilai $\%$ terdisolusi yang kecil ini dipengaruhi oleh kelarutan dari zat aktif teofilin yang sukar larut dalam air. Pada disolusi menggunakan aquadest sebagai mediumnya dengan suhu $37^{\circ} \mathrm{C}$ dengan metode dayung. Tablet terlihat sudah hancur namun proses pelarutan yang

Tabel 5. Kadar Teofilin Terdisolusi (\%)

\begin{tabular}{cccccc}
\hline Menit & F1 & F2 & F3 & F4 & F5 \\
\hline 5 & 6,18 & 8,30 & 1,687 & 9,59 & 5,39 \\
10 & 8,50 & 11,04 & 2,28 & 21,53 & 6,03 \\
15 & 12,34 & 12,65 & 3,85 & 15,82 & 7,32 \\
30 & 8,99 & 20,58 & 5,299 & 19,47 & 8,05 \\
45 & 8,42 & 17,58 & 6,24 & 22,01 & 8,94 \\
\hline
\end{tabular}




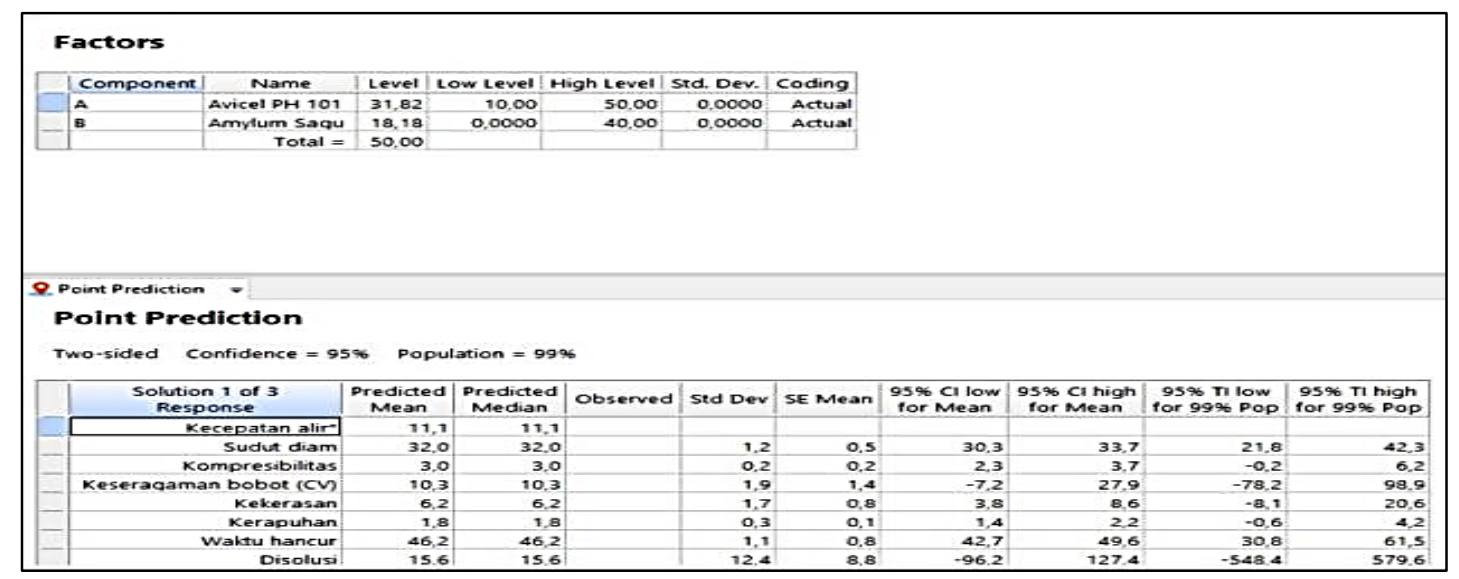

Gambar 2. Model Graphs Analisis SLD

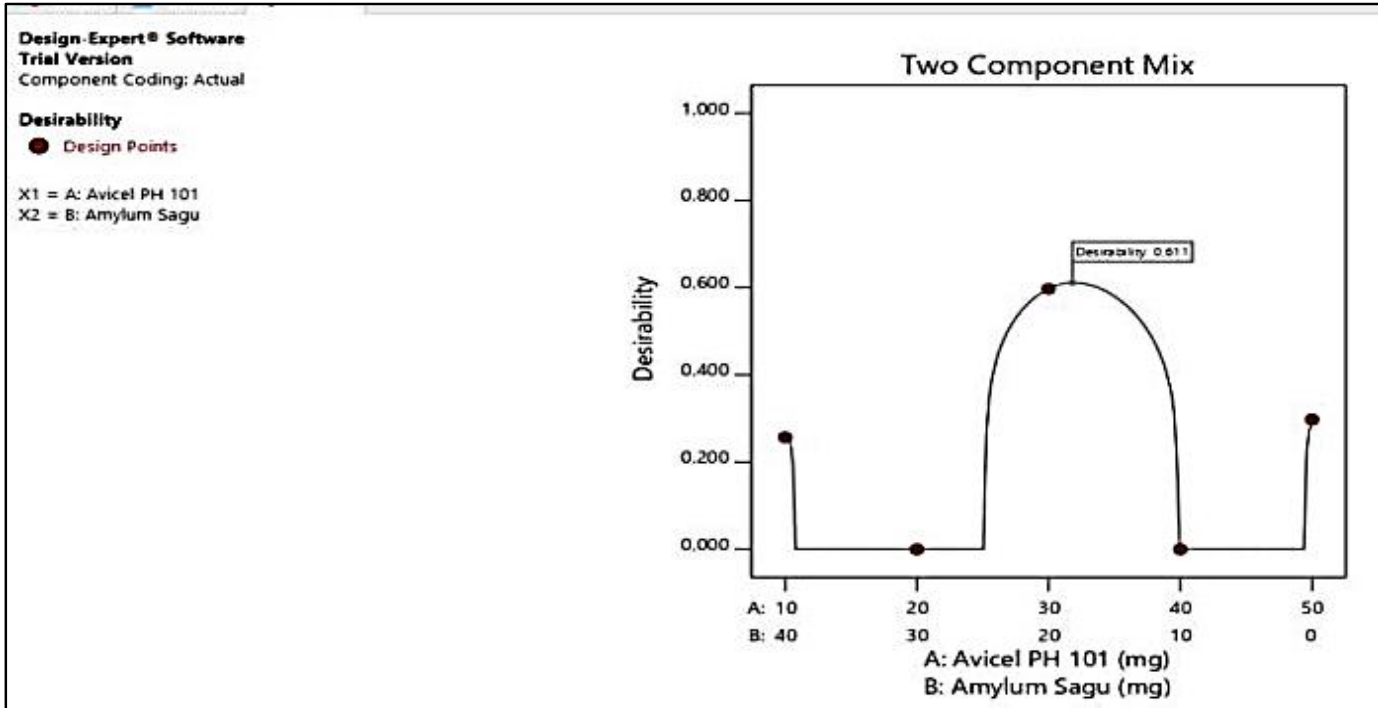

Gambar 3. Model Graphs Desirability

terjadi tidak maksimal sehingga zat aktif yang terdisolusi memiliki nilai yang kecil. Kadar yang terdisolusi menggambarkan zat aktif dalam tablet yang dapat diabsobsi yang kemudian akan didistribusikan dan dimetabolisme oleh tubuh.

Data hasil percobaan yang dianalisis menggunakan software Design Expert Simplex Lattice Design diperoleh kombinasi optimum dengan $50 \%$ pasta amylum; $18 \%$ amylum sagu; dan 31,82\% avicel PH 101 (Gambar 2). Parameter uji dapat di prediksi nilai optimumnya yaitu, Kecepatan alir 11,1g/dtk; sudut diam 32,0; kompresibilitas
3,0\%; keseragaman bobot cv 10,3; kekerasan $6,2 \mathrm{~kg}$; kerapuhan $1,8 \%$; waktu hancur 46,2 dtk dan disolusi 15,6\%.

Desirability adalah kriteria dari formula yang dapat diterima, nilai desirability yang baik yaitu lebih dari 0,5 . Formula yang dapat diterima berdasarkan hasil parameter uji yang di analisis menggunakan software Design Expert, diperoleh nilai desirability 0,611 (Gambar 3). Dengan hasil ini komponen kombinasi yang diterima adalah $18,18 \%$ amylum sagu; dan 31,82\% avicel PH 101.

PHARMACON: Jurnal Farmasi Indonesia Vol 14, No 2 (2017) ISSN 1411-4283 


\section{KESIMPULAN}

Berdasarkan analisis data hasil penelitian menggunakan software Design Expert, avicel PH 101 meningkatkan kekerasan tablet sedangkan amylum sagu meningkatkan kerapuhan tablet, kombinasi bahan tersebut agar diperoleh sifat tablet yang optimum adalah $50 \%$ pasta amylum; $18,18 \%$ amylum sagu; dan 31,82\% avicel PH 101.

\section{UCAPAN TERIMAKASIH}

Terima kasih kepada Kemenristekdikti atas dana yang telah diberikan melalui PKMPE dan kepada PT. Konimex yang telah memberikan bahan Crosscarmellose Sodium untuk menjalankan penelitian ini.

\section{DAFTAR PUSTAKA}

Departemen Kesehatan Republik Indonesia. 2014. Farmakope Indonesia. Edisi V. Departemen Kesehatan Republik Indonesia. Jakarta.

Gohel, M.C., and Jogani, P.D., 2003. Investigation of direct compression characteristics of coprocessed lactose-starch using factorial design. Indian J Pharm Sci. 65 (1): 31-38.

Gohel, M. C. 2005. A Review of Co-processed Directly Compressible Excipients. J. Pharm Sci, 8 (1): 76-93.

Hadisoewignyo, L., dan Fudholi, A., 2013. Sediaan Solida. Pustaka Pelajar. Yogyakarta.

Hauschild, K., and Picker, K.M. 2004. Evaluation of New Coprocessed Compound Based on Lactose and Maize Starch for Tablet Formulation. Pharm Sci Tech. 6 (2).

Jaynes, J., Ding, X., Xu, H., Wong, W. K., and Ho, C. H. 2014. An Application of Fractional Factorial Designs to Study Drug Combinations. National Institutes Of Health. 32 (2): 2.

Tomar, M., Sinha, AR., and Singh, AK. 2017. Process and Development of Co-Processed Excipient Silicified Microcrystalline Cellulose and Manufacture Paracetamol Tablet by Direct Compression. International Journal of Pharmaceutical Sciences Review and Research. 42 (1): 191-196.

Trache, D., Hussin, MH., Chuin, CTH., Sabar, S., Fazita, MRN., Taiwo, OFA., Hassan, TM., and Haafiz, MKM. Microcrystalline cellulose: Isolation, characterization and biocomposites application-A review. International Journal of Biological Macromolecules. 93 (2016): 789-804.

Kuentz, M., Holm, R., Elder, D. 2016. Methodology of Oral Formulation Selection in The Pharmaceutical Industry. European Journal of Pharmaceutical Sciences. 87: 136-163.

Kulkarni, MC., and Kolhe SV. 2016. Formulation Development and Evaluation of Atorvastatin Calcium Tablets using Co-Processed Excipients. International Journal of Pharmaceutical Sciences Review and Research. 36 (1): 217-222.

Lachman L., Lichberman HA, Kanig JL, eds. 2014. The theory and Practice of Industrial Pharmacy. 3rd ed. Lea and Febiger. Philadelphia. 
Limwong, V., Sutanthavibul, N., and Kulvanich, P. 2004. Spherical Composite Particles of Rice Starch and Microcrystalline Cellulose: A New Coprocessed Excipient for Direct Compression. Pharm Sci Tech. 5 (2).

Muzikova, J., Srbova, A., Svacinova, P. 2016. A study of a novel co-processed dry binder composed of $\alpha$-lactose monohydrate, microcrystalline cellulose and corn starch. Pharmaceutical Development and Technology. 22(8): 964-971.

Zhang, Y., Law, Y., and Chakrabarti, S. 2003. Physical Properties and Compact Analysis of Commonly Used Direct Compression Binders. Pharm Sci Tech. Vol. 4. 